\title{
Management Development and Organizational Resilience. A Case Study Of Some Selected Manufacturing Firms In Rivers State. Nigera.
}

\author{
G.I. Umoh, Ph.D, MAMN, E. Amah, Ph.D, MNIM, H. I. Wokocha Ph. D, \\ MNIM \\ ( Associate Professor, Department of Management, University of Port Harcourt) \\ (Senior Lecturer, Department of Management, University of Port Harcourt) \\ (Chief Lecturer, Department of Office Technology and Management, School of Management, Rivers State \\ College of Arts and Science, Rumuola, Port Harcourt)
}

\begin{abstract}
The study examined the effect of Management Development on Organizational Resilience in the Nigerian manufacturing industry. A total of 140 employees were randomly drawn from employees of the 31 manufacturing companies in Port Harcourt. The instruments used for data collection were questionnaire and oral interview. A total of 93 copies of the questionnaire were retrieved and analyzed. Spearman's Rank Correlation Statistical tool was used to test the hypotheses. The findings revealed that Management Development is significantly related to Organizational Resilience. Based on these findings we concluded that Management Development has significant influence on Organizational Resilience. The study therefore recommends that organizations should use its management development programmes as a knowledge retention measure that will strategically channel efforts in a way that will drive organizational success.

Key words: Management development, Organizational resilience, Organizational learning, Adaptive capacity, Dynamic capabilities.
\end{abstract}

\section{Introduction}

Managers are constantly striving to improve the performance of their organizations. Regardless of the type of and purpose of an enterprise, its leaders seek to enhance the way an organization conducts its business by adopting management practices which aim to increase effectiveness, efficiency and safety, also being resilient. To be resilient, organizations rely on strong leadership, their awareness and understanding of their operating environment, their ability to manage vulnerabilities and their ability to adapt in response to rapid change. Alastir (2010) asserts that as our society becomes more complex and independent, we are becoming more vulnerable to disruptive events from threats and hazard.

Alastir contends that the aim of building resilience is to remove or reduce the exposure of organizations to threats and hazards by developing protective measures which aim to reduce the likelihood and consequences of a disruptive event, by preventing when possible, responding effectively and efficiently when an event occurs, and by recovering as quickly and completely as possible. Seville et al. (2008) discuss organizational resilience as an organization's “... ability to survive, and potentially even thrive, in times of crisis". Organizational resilience is a continuously moving target which contributes to performance during business-as-usual and crisis situations (Mitroff, 2005). It requires organizations to adapt and to be highly reliable (Weick \& Sutcliffe, 2007), and enables them to manage disruptive challenges (Durodie, 2003).

Over the past decade, a great deal has been written about Management development and the role it plays in successful resilience of organizations (Clark, 1993; Mallak, 1998; Stamp, 2000; Williams et al., 2002; Durodie, 2003; Dalziell \& McManus, 2004, Mitroff, 2005; Weick and Sutcliffe, 2007; Serville et al., 2008; Umoh, 2009; Amah, 2010; Alastir, 2010). Despite these numbers of studies, little empirical studies exist on Management development and Organizational resilience in developing countries especially in Nigeria. To bridge this gap, this study examines the effect of Management development on Organizational resilience. By exploring the relationship between Management development and Organizational resilience, organizations can enhance their competitive advantage and effectiveness.

\section{Literature Review}

\section{Management Development}

According to Mullins (1999), management is the cornerstone of organizational effectiveness and the contribution to social needs of the society. This applies to public sector and service organizations as to many other industries. Managers need a balance of technical, social and conceptual knowledge and skills, acquired 
through a blend of education and experience. There is therefore a continual need for managerial development of both present and future managers.

Development is concerned with preparing the manager for expected changes in the job, or for anticipated future job or role. However, management development is meant to include an element of training. For Mullins, a more general interpretation views management development as an integral part of the process of organizational development. '....Manager Development must embrace all managers in the enterprise. It must aim at challenging all to growth and self development. It must focus on performance rather than on promise, and on tomorrows requirements rather than those of today's' (Drucker, 1955).

Management development is defined in the web dictionary as the process from which managers learn and improve their skills not only to benefits themselves but also their employing organizations. Managers are exposed to learning opportunity whilst doing their jobs, if this informal learning is used as a formal learning process then it is regarded as management development. Business Dictionary (2012) defines management development as an aspect of organizational development that covers recruitment and assessment of executive level employees and training them in leadership to equip them for higher positions. This process generally includes development of cognitive (thinking, idea generation and decision making) behavioural (choosing appropriate attitudes and values) and environmental (suiting management style to the situation) skills.

William, James and Susan (2002) define management development as the process of training and educating employees to become good managers and their monitoring the progress of their managerial skills over time.

Management development is increasingly being used as a tool to accomplish business objectives. According these authors, most management training programs also include several of the following:

1. On - the - job couching: This means that a senior manager will assist a lower - level manager by teaching him or her needed skills and generally providing directions, advice, and helpful criticism.

2. Understudy Position: Job titles such as undersecretary and assistant are part of a relatively successful way of developing managers. Selected employees work as assistant to higher level managers and participate in planning and other managerial functions until they are ready to assume such positions themselves.

3. Job Rotation: So that they can learn about different functions of the organization managers are often given assignments in a variety of departments. Through job rotation, top managers gain the broad picture of the organization necessary to their success.

4. Off - the - job Course and Training: Managers periodically go to schools or seminars for a week or more to hone their technical and human relations skills. Such courses exposed them to the latest concepts and create a sense of camaraderie as the managers live, eat, and work together in a college type atmosphere case studies and simulation exercise of all kinds are often part of such training.

According to Amah (2010), The aim of management development is to make sure that the men set aside as future executive are properly trained, and ready for action, by the time they are due to take their appointed place in the overall plan. Amah contend that in selecting for top management, - director level, whether from inside or by external talent spotting, it may be considered advisable to use sophisticated tests designed to demonstrate managerial ability and general group effectiveness. She recommends a group approach which extends to such organized procedure as so- called "Psychological week - end' or 'country house' conditions, where candidates take part in public-speaking sessions, group discussion, debates, exercise, etc., and are closely studied by specialist on all points of view. This includes an assessment of their social ability to mix well, to take part in intelligent conversation, and to conduct themselves correctly at table. She outlined some management development programmes as noted below

1. Students Scholarship

2. Professional and Technical Qualifications

3. General Management Development

4. Diploma in Management studies

Agulanna and Awujo (2005) assert that management development is concerned with the improvement of managers' performance in their current roles and preparing them for greater responsibilities in the future. They posit that management development covers a wide range of activities such as

- $\quad$ Self- development through improving communication and presentation skills.

- Specific skills such as managing information in the office, performance appraisals, financial management, managing other people, and managing in different cultures.

According to Stamp (2000) cited in Agulanna and Awujo (2005), "in a climate in which managers are expected to use their judgment and trust their intuition, and encourage others to do the same, management development must include concepts such as learning to learn, listening, being a team member, influencing others, communication and individual understanding of growth capability" organizations need creative people who can act on their own initiative whether in serving customers or in making products because the survival of an organization depends on its ability to be flexible and adaptive in a highly competitive environment. 
In a 1990 survey of C.E.Os around the world showed their priorities for developing managers as follows, according to Stamp (2000).

- $\quad$ Strategic Awareness (mentioned by $71 \%$ of those surveyed)

- $\quad$ Adaptability in new situation (67\%)

- $\quad$ Sensitivity in different cultures $(60 \%)$

- $\quad$ Ability to work in international teams (58\%)

- $\quad$ Relationship skills $(40 \%)$

- $\quad$ High task orientation (19\%)

It should be noted that single most powerful driver of management development will be global and personal information technology. The internet is already tapped by organizations all over the world for information which can be used for competitive advantage. This spread of information also has a profound effect on individual development.

Clarke (1993) refers to the changing role of the manager and suggests that the manager of the future will have to master three specific roles, or survival skills- leader, couch and facilitator.

1) The role of leader involves the skills of focusing on the wider picture, involving employees in implementation and establishing an environment in which people can operate and have enough space for creativity.

2) The role of couch- involves the skills of creating an environment where change can thrive, and bringing abilities to the surface by building up confidence and building up on capabilities.

3) The role of facilitator involves the skills of moving the organization forward and achieving continuous improvement in performance, encouraging the growth of new idea and bringing the best out of employees.

Mullins and Aldrich (1998) have constructed an integrated model of managerial behavior and development. The model relies on basic management and behavioral theories for its structure, and situational demands for its adaptation.

1) Past knowledge and experience: Development involves a combination of knowledge and varied experience. These are seen as taking place through a combination of both theoretical and practical involvement.

2) Behavioral and social variables provide a framework for conceptualizing behavior in organizations and include:

- Links with other individuals and groups within and outside the organization. These links may be formal or informal.

- Personality and people perception.

- Values

- Attitudes

- Opinions

- Intelligence and abilities: Learning and skills acquisition and the assimilation and retention of past knowledge.

- Motivation: Needs and expectations.

3) Analyzing Organization: The organization can be analyzed in terms of five main interrelated sub-systems. Two of these, people and management, can be considered within the context of the behavioural and social variables above.

- Task- organization, the nature of its inputs and outputs, and work to be carried out during the work process.

- Technology - Describes the manner in which the tasks of the organization are carried out and the nature of the work performance. The materials, techniques, and equipment used in the transformation or conversion process.

- $\quad$ Structure - Defines the pattern of organization and formal relationships among members. The pattern of organization and formal relationships among members. The division of work and co-ordination of tasks by which any series of activities can be carried out.

- $\quad$ People - The nature of the members understanding the series of activities as defined by the behavioural and social variables.

- Management - Is therefore the integrating of activities working to achieve the 'tasks' using the 'technology'.

The development of executives is the development of the organization.

\section{Resilience}

Madni (2007) Defines resilience as the ability to anticipate a perturbation, to resist by adapting and to recover by restoring the pre-perturbation state as much as possible. McManus et al.; (2008) asserts that the numerous 
concepts that emerge from definitions of organizational resilience include knowledge of the environment, level of preparation, anticipation of perturbations, adaptation, capacity to recover, etc. The ability of organizations to absorb shock or develop resistance in the face of perturbances within its environment is a reflection of how prepared the organization can be.

Alastir (2010) contends that managers of resilient organizations should understand at board level, the environment in which their organizations operates, and be aware of changes which may represent a risk to their people, facilities, activities, services and supply chains. He maintains that managers need to understand the increasing complex cultural, political, legal, regulatory, economic, technological, natural and competitive context within which they operate and monitor key issues and trends that may impact on the objectives of the organization and the perceptions and values of external stakeholders.

Erica (2006) asserts that the economic implication of organizations being unprepared for crisis are significant. In September $11^{\text {th }}$ attacks, business interruption losses far exceeded the sum of all property losses. The importance of organizations being resilience can be well appreciated when we examine the decline in talented skills in certain workforces due to some unanticipated disaster or crisis or loss of key executives either as a result of death or being incapacitated to perform their duties.

In their argument, Amah and Daminabo-Weje (2004) are of the opinion that successful organization were those who understood the dynamic nature of their environment (Competitors, technology, the availability and cost of finance, taxation, government policy and their customer needs and expectations). In this regard, they contend that a successful organization should evolve like a resilient eco-system constantly adopting to reflect the changing external environments. According to a United Nations Report (2003) events such as the 1998 ice storm in Quebec and Ontario and the August 2003 black out that affected 50 million people in the Midwestern and Eastern U.S.A and Ontario made governments realize that it had become crucial to develop a culture of resilience within organization. The restless and chaotic business operations make organizations vulnerable to a multiplicity of risks at all times. These environments require organizations to be flexible, adaptable and creative enough to respond to changing conditions which implies resilience for the organizations.

Smith (2002) describes organizational resilience in the context of being concerned with crisis prevention. According to Smith, there are two wide areas of crisis prevention. The first is concerned with the development of a crisis preparation culture; the second area is concerned with the ethical aspects of corporate behaviour and the creation of resilience as a consequence of suspect ethical behaviour.

Mallak et al (1997) identified four tools that will be used to help better prepare for crisis: (1) Risk analysis, (2) Contingency plan (3) Logic charts and (4) Tabletop exercises.

Stucliffe and Vogus (2002) believe that resilience "results from processes that promote competencies, restore efficacy, and encourage growth as well as structures and practices that enable these processes". According to Robb, a resilient organization "is able to create structure; dissolve it; provide safety in the midst of change; manage the emotional consequences of continuous transformation and change (anxiety and grief); and learn, develop, and grow".

The September 11 attacks and their aftermath are a living laboratory for those wishing to better understand how individuals, groups, and organizations respond under extreme disaster conditions. Along with other major disaster events, 9/11 revealed much about institutional responses and collective behavior in crises, underscoring what is already known about the social processes that characterize such events, while at the same time highlighting aspects of disasters that the literature has yet to explore fully (Tierney, 2001). Interesting data have emerged from reports written after 9/11. One such report looked at resiliency factors that could be implemented in private industry and the banking business based on what was learned from the attacks at the World Trade Center.

McManus's (2007) definition and indicators of organizational resilience, which she called, Relative Overall Resilience (ROR), is based on a definition of organizational resilience as, “...a function of an organization's situation awareness, management of keystone vulnerabilities and adaptive capacity in a complex, dynamic and interconnected environment". This definition identifies three components or dimensions of organizational resilience; situation awareness, management of keystone vulnerabilities, and adaptive capacity. McManus (2007) also identified fifteen indicators of organizational resilience, five for each dimensions. Tierney (2003) talks about, robustness redundancy, resourcefulness and rapidity, as well as four domains; technical, organizational, social and economic.

\section{Measures of Organizational Resilience}

The measures of Organizational resilience include Organizational Learning, Adaptive capacity and Dynamic Capability. 


\section{Organizational Learning}

Organizational learning has been defined in the web dictionary as an Organization-wide continuous process that enhances its collective ability to accept, make sense of and respond to internal and external change. Organizational learning requires systematic integration and collective interpretation of new knowledge that leads to collective action and involves risk taking as experimentation.

Organizational Learning is an area of knowledge within organizational theory that studies models and theories about the way an organization learns and adapts. In organizational development (OD) is as characteristic of an adaptive organization, ie, an organization that is able to see changes in signals from its environment (both internal and external) and adapt accordingly. Learning is acquiring new, or modifying existing knowledge, behaviors, skill, values, or preferences and may involve synthesizing different types of information. knowledge.

Aggestam (2006) posits that a learning Organization has a culture that supports learning and innovations both by individuals and by the organization. The environment promotes a culture of learning, a community of learners, and it ensures that individual learning enriches and enhances the organization as a whole. The process of learning must ultimately be made part of the culture, not just be a solution to a given problem. Learning organizations demand a new view of leadership, leader as designer. Culture begins with leadership, but because culture is the result of a group's accumulated learning the culture itself will later define the wanted leadership.

The first step in building a learning organization requires a leader who inspires the vision of the learning organization. To be a learning organization has no value in itself, it must always serve the broader aims of the organization. Shared visions emerge from personal visions. A Learning Organization has a design and a culture which takes in, and in a learning organization members know why. In other organizations they know how. Aggestam(2006) maintains that a learning organization is organized in such a way that it scans for information in its environment, creates information by itself, and encourages individuals to transfer know-ledge between the individuals in team. This must be guided by the structure and by the vision that is guided by the strategic leadership of the organization.

Learning is when changes in knowledge happen inside an individual and learning and accumulation of (new) knowledge always starts with the individual. Individual learning does not necessarily imply changes in organizational knowledge. Organizational knowledge is knowledge independent of specific members in the organization, e.g. knowledge in know-ledge repositories, and knowledge embedded in policies, and routines. Organizational Learning (OL) is considered to depend on the collective cognitive processes of individuals. Individuals can be regarded as subsystems in the organization. The concept of learning organization regards the organization as an entity and focuses what are the characteristics such that encourages its members may learn. Organizational learning, on the other hand, focuses on how learning is developed in an organization.

\section{Adaptive Capacity}

In socio-ecological context, Walker et al., (2002) define adaptive capacity as an aspect of resilience that reflects learning, flexibility to experiment and adopt novel solutions, and the development of generalized responses to broad classes of challenges. Folke et al., (2003) identified four dimensions of adaptive capacity:

- $\quad$ Learning to live with uncertainty

- $\quad$ Nurturing diversity for reorganization and renewal

- $\quad$ Combining different types of knowledge for learning

- $\quad$ Creating opportunities for self-organization.

Armitage (2005) adapts Folke et al.,'s (2003) four dimensions for socio-institutions. In a socio-institution context, adaptive capacity depends on the attributes of individuals, organizations and institutions that might foster learning when faced with change and uncertainty, such as willingness to learn from mistakes, engage in collaborative decision-making arrangements, and encourage institutional diversity.

Adaptive capacity may be defined as the ability or inclination of individual or group to maintain an experimental attitude towards new situations as they occur and to act in terms of changing circumstances. Adaptive capacity is addressed in this context through two approaches; socio environmental, and organizational (McManus, 2007). An organization's ability to adapt is at the heart of their ability to display resilient characteristics. Amah and Baridam (2012) discuss the importance of adaptation and note that the aim is to create advantages over less adaptive competitors. This suggests that adaptive capacity is also linked to competitiveness.

Dalziell and McManus (2004) define adaptive capacity as, the engagement and involvement of organizational staff so that they are responsible, accountable and occupied with developing the organization's resilience through their work because they understand the links between the organization's resilience and its long term success. "...the ability of the system to respond to changes in its external environment, and to recover from damage to internal structures within the system that affect its ability to achieve its purpose". They also define adaptive capacity as relating to strong leadership and a culture which 
enables clear communication, good working relationships, and a shared vision across the organization. The organization is innovative and creative and people are able to constantly and continuously act to match or exceed the needs of the organization's operating environment in anticipation of, or in response to change. Dalziell and McManus (2004) go on to demonstrate the difference between adaptive capacity and vulnerability, which they argue are often used interchangeably because of the inclusion of adaptation in definitions of vulnerability. Vulnerability is defined by Dalzille and McManus (2004) as the amount of deviation from the organization's original state to the point at which it experiences significant change or impacts as a result of the disaster. Adaptive capacity then, is the envelope or space in which the organization's performance or management of the disaster fluctuates until it reaches an equilibrium.

Indicators AC1 to AC5 are McManus's (2007) indicators of adaptive capacity within her Relative Overall Resilience (ROR) model, and indicators AC6 and AC7 have been added as part of the updated model.

- AC1 - Minimization of Silo Mentality

- AC2 - Communications and Relationships

- AC3 - Strategic Vision and Outcome Expectancy

- AC4 - Information and Knowledge

- AC5 - Leadership, Management and Governance Structures

- AC6 - Innovation and Creativity

- AC7 - Devolved and Responsive Decision Making

\section{Dynamic Capabilities}

Teece, et al. (2010) defined Dynamic capabilities as "the firm's ability to integrate, build, and reconfigure internal and external competencies to address rapidly changing environments". Dynamic capabilities can be distinguished from operational capabilities which pattern to the current operations of an organization. Dynamic capabilities, by contrast, refer to "the capacity of an organization to purposely create, extend, or modify its resource base" (Helfat et al, 2007) cited in Teece, et al., (2010). The basic assumption of the dynamic capability is framework is that core competencies should be used to modify short-term competitive positions that can be used to build longer-term competitive advantage. These authors affirm that the Literature on dynamic capabilities grew out of (1) the resource based view of the firm and (2) the concept of "routines" in evolutionary theories of the organization (Nelson and Winter, 1982) cited in Teece, et al (2010).It thus provides a bridge between the economic-based strategy literature and evolutionary approaches to organization. They opine that three dynamic capabilities are necessary in other to meet new challenges. Organizations and their employees need the capability to learn quickly and to build strategic assets. New assets such as capability, technology and customer feedback have to be integrated within the company. Existing strategic assets have to be transformed or reconfigured. Treece's concept of dynamic capabilities essentially says that what matters for business is corporate agility; " the capacity (1) to sense and shape opportunities for threat, (2) to seize opportunities, (3) to maintain competitiveness through enhancing, combining, protecting, and when necessary, reconfiguring the business enterprise's intangible and tangible assets.

\section{Relationship between the Independent and Dependent variable Relationship between Management Development and Organizational learning.}

The literature on organizational learning focuses on how organizations successfully acquire, share, and use knowledge to achieve organizational goals. There is a strong emphasis for creating 'knowledge for action', not knowledge for its own sake (Agyris 1993). Further, it recognizes that organizations are a part of complex social systems, systems over which it is unlikely they can exert control. Another aspect of the pragmatic orientation is that learning organization theorists, unlike many of their academic counterparts, have also developed an array of techniques and tools for doing diagnostics, examining patterns of behaviour in organizations, and engaging in 'transformative thinking' (Wycoff 1995). There is also a strong element of 'self-improvement' found in the literature, whereby individuals in a learning organization are not only in an ongoing quest for work-related knowledge, but also for self knowledge. One aspect of this is the need to understand their own 'mental models' - deeply ingrained assumptions about how the world works, what motivates people, cause-and-effect relationships - and to be open to challenges regarding these assumptions.

Individuals as well as the organization are engaged in an ongoing quest for knowledge, their struggle to 'unlearn' dysfunctional behaviours is continuous, and because change is a constant, they must constantly change. Developing managers is a learning process that enhances organizational learning. This can be achieved by reviewing and assessing talent employees who should fit into higher roles when the need arises. Methods may include.

(1) Identify the development needs.

(2) Identify employees with talents.

(3) Identify positions that are threading. 
(4) Assess the environment, competitor's activities.

(5) Information sharing is important for the progress of the organization.

\section{Management Development and Adaptive Capacity}

Staber and Sydow (2002) discuss 'adaptation' and 'adaptive capacity' as two approaches to organizational effectiveness and survival in hypercompetitive environment. They assert that continual learning along with a mindset and conditions that are supportive for the learning is at the core of adaptive capacity. This comes as no surprise; organizational learning and adaptation are among the literatures that speak most directly to understanding organizational resilience (Sutcliff and Vogus, 2003). Developing managers through learning is an essential way of ripping off failure in terms of loss of knowledge in organizations.

\section{Relationship between Management Development and Dynamic Capabilities.}

Teece (2011) asserts that the most important intangible asset that organizations have to deal with is technological know- how and other intangibles are increasingly the "bottleneck assets" that allow innovating firms to differentiate and establish some degree of competitive advantage. Knowledge and information are intangible assets which are used for developing managers to ensure that the organization has all the HR needs required to operate in a dynamic environment. This further forestalls the organization against threats from its competitors and other external factor that might disrupt the enterprise.

By training and retraining, enriching and enlarging jobs, job rotation, simulation and scenario exercises, management is saying we are ready to absorb any form of shock, anticipatorily to prepare to cushion whatever environmental disturbance that may arise. It then means that by preparing employees by enriching them with the required skills and knowledge to manage not just their particular job but also to be able to step into the shoes of superiors or talented executives when vacancy exist, the organization is guarding itself against failure.

Agulanna and Awujo (2005) asserts that human beings are the agents who accumulate wealth, exploit material resources, build social, economic, and political organizations and achieve national development. When they are trained, they become more effective and efficient in the above exercises. It is pertinent at this point to bring in the Paul Principle which states "overtime, people become uneducated and therefore incompetent to perform". The implication of the principle is that training and retraining are imperative. Training is needed when organization goals can be advanced by improved employee-performance. Employee performance is required to keep the organization going and that is a way of possessing dynamic capabilities. From the foregoing, the following hypotheses were obtained:

$\mathrm{HO}_{1}$ : $\quad$ Management development does not have any significant effect on organizational learning.

$\mathrm{HO}_{2}$ : $\quad$ Management development does not have any significant effect on adaptive capacity.

$\mathrm{HO}_{3}$ : $\quad$ Management development does not have any significant effect on dynamic capabilities.

\section{Research Methodology}

This correlational study was conducted as a cross-sectional survey. The study units for data generation were employees in 31 registered and functional manufacturing companies in Port Harcourt and the micro-level of analysis was adopted. A sample size of 140 employees was determined using the Taro Yamen's formula (Baridam, 2001). After cleaning, 93 copies of the instrument were used for the analysis. In selecting the respondents the simple random sampling technique was adopted. A four-item scale was developed for management development based on Mullins and Aldrich (1998).

The dependent variable is Organizational resilience. The measures of Organizational resilience includes organizational learning, adaptive capacity, dynamic capabilities. Organizational learning - A five-item scale was developed based on Watkins and Marsick (2000). Adaptive capacity - A five-item scale was developed based on Folke et al., (2003). Dynamic capabilities- A five-item scale was developed based on Teece et al., 2010. A five-point Likert type scale was used (ranging from 5-strongly agree to 1-strongly disagree) for all.

For test of reliability of the scale, the following Cronbach's alpha coefficients were obtained: Management development (0.72), Organizational learning (0.83), Adaptive capacity (0.80), Dynamic capabilities (0.75). In accordance with Nunnaly (1978) model, which recommends a bench mark of 0.70 , the reliability levels of the study scale are acceptable. Spearman's Rank Correlation Statistical tool was used to test the hypothesis. The result as presented was obtained.

\section{Research Results And Findings}

Frequencies and descriptive were used in our primary analysis which focused on the study demographics and univariate analysis respectively. The results show that $68 \%$ of the respondents were males while $32 \%$ were females. $23.66 \%$ of the respondents are between $21-30$ years old while $34.41 \%$ are between 31 and 40 years old. $26.88 \%$ of the respondents are between $41-50 y e a r s$ old. On educational qualification, we had 
the following distribution: $46.24 \%$ Diploma, 37.63\% HND/BSc, $16.13 \%$ Masters. $26.9 \%$ of the respondents had stayed between 3-5 years. 35.5\% have stayed 6-10 years, 37.6\% had stayed above 10 years.

HYPOTHESIS 1 ( $\left.\mathrm{Ho}_{1}\right)$ : Management development does not have any significant effect on Organizational learning. Nonparametric Correlations

\begin{tabular}{|c|c|c|c|c|}
\hline & & & Mgt. Dev & Org. L \\
\hline \multirow[t]{6}{*}{ Spearman's rho } & \multirow[t]{3}{*}{ Mgt Dev } & Correlation Coefficient & 1.000 & $.903^{\text {** }}$ \\
\hline & & Sig. (2-tailed) & & .000 \\
\hline & & $\mathrm{N}$ & 93 & 93 \\
\hline & \multirow[t]{3}{*}{$\mathrm{OL}$} & Correlation Coefficient & $.903^{* *}$ & 1.000 \\
\hline & & Sig. (2-tailed) & .000 & \\
\hline & & $\mathrm{N}$ & 93 & 93 \\
\hline
\end{tabular}

The table above indicates that there exists a positive relationship between management development and organizational learning. The rho indicates a value of .903 at a significant value of 0.000 . Since it falls within the 0.05 level of our preferred level of confidence, the null hypothesis is rejected while the alternative is accepted. This implies that Management development has a significant effect on Organizational resilience. The correlation coefficient of 0.903 indicates that there is a strong positive correlation.

Ho $_{2:}$ Management development does not have any significant effect on Adaptive Capacity. Nonparametric Correlations. Correlations

\begin{tabular}{|lll|r|r|}
\hline & & Mgt. Dev & \multicolumn{1}{c|}{ Adapt. Cap } \\
\hline Spearman's rho & Mgt Dev & Correlation Coefficient & 1.000 & $.871^{* *}$ \\
& Sig. (2-tailed) &. & .000 \\
& $\mathrm{~N}$ & 93 & 93 \\
\cline { 2 - 5 } & Adapt. Cap & Correlation Coefficient & $.871^{* *}$ & 1.000 \\
& Sig. (2-tailed) & .000 &. \\
& $\mathrm{~N}$ & 93 & 93 \\
& & &
\end{tabular}

**. Correlation is significant at the 0.01 level (2-tailed).

The above table shows that there exists a positive and significant relationship between Management development and Adaptive capacity. The rho value is 0.871 at a significant value of .000 falls within the critical value at a 0.05 level of confidence; hence the null hypothesis is rejected while the alternative which states that Management development has a significant effect on Adaptive Capacity is accepted.

Ho $:$ Management development does not have any significant effect on Dynamic capability. Nonparametric Correlations

Correlations

\begin{tabular}{|lll|r|r|}
\hline & & Mgt. Dev & \multicolumn{1}{|c|}{ Dyn. Cap } \\
\hline Spearman's rho & Mgt Dev & Correlation Coefficient & 1.000 & $.921^{*}$ \\
& & .000 \\
& Sig. (2-tailed) & 93 & .000 \\
& $\mathrm{~N}$ & $.921^{* * *}$ & 93 \\
\cline { 2 - 4 } & CL & .000 & 1.000 \\
& Correlation Coefficient & 93 &. \\
& Sig. (2-tailed) & 93 \\
& $\mathrm{~N}$ &
\end{tabular}

The above table shows that there exists a statistical significant relationship between the variables. The significant value of 0.000 showed higher value and lies within the preferred critical value of $0.05(95 \%)$ confidence level, therefore the null hypothesis which states that management development does not have any significant effect on dynamic capabilities is rejected and the alternative is accepted. Hence management development has a significant effect on dynamic capabilities. The coefficient of correlation $\mathrm{R}$ shows a 0.921 $(90.2 \%)$ value implies that there is a high and positive correlation. This means that the variables are moving in the same direction. 


\section{Dicussion, Conclusion And Recommendation}

The three hypotheses sought to examine the effect of management development on the measures of organizational resilience (organizational learning, adaptive capacity and dynamic capabilities). Theses hypotheses were tested using spearman rank correlation technique. From the analysis of collected data (see Tables above), a positive relationship was revealed between management development and measures of organizational resilience. This findings may be explained by the fact that in Nigeria, manufacturing companies are adopting management development programmes in their human resource management practices to ensure they have the required skills and talents that can compete favorably with the world at large and ensure that in the event of natural disaster or any other form of business catastrophe, loss of key employees etc they are sure to have a pool of talent that can keep the entire corporation going without extinction of the entity.

Based on the discussions above, we conclude that Management development significantly affects organizational resilience (organizational learning, adaptive capacity and dynamic capabilities) within the Nigeria work environment and the manufacturing sector to be specific.

\section{Based on the above discussions, we recommend that:}

In order to ensure sustainability and growth organizations, such as the ones at which the survey was conducted, should focus on the factors that positively impact on their organizational resiliency. Organizations should align their HR programmes with the current demands of our time and through thorough environmental scanning install the right talents that can responsively beat their competitors. They should also develop strategies that can prevent and prepare the business to withstand other forms of business disruptions.

\section{References}

[1]. Aggestam, L. (2006) Learning Organization or Knowledge Management- Which comes first, the chicken or the egg? Information Technology and Control Journal. Vol.35, No 3A ISSN 1392-124x. School of Humanities and Informatics, University of Skoevde. Sweden.

[2]. Agyris,C (1993) On Organizational Learning. Cambridge, MA: Blackwell.

[3]. Agulanna, C. Edward and Awujo, C. Austine (2005) Human Resource Management - A graphic Approach. Imo State. Career publishers.

[4]. Alastir M. (2010) Organizational Resilience. Understanding the concept and its application. Torrens Resilience Institute. Australia.

[5]. Amah, E (2010) Human Resource Management. Amethyst \&Colleagues Publishers, Port Harcourt

[6]. Amah, E. and Daminabo-Weje, M. (2004) Fundamentals of Management. Davidstone Publishers. Port Harcourt

[7]. Amah, E. and Baridam, D. (2012) Adaptability and Organizational Effectiveness. A Study of the Nigerian Banking Industry. International Journal of Business Management Tomorrow. Vol. 2 No 3, 2012. Pg 122-131

[8]. Armitage, D. (2005) Adaptive capacity and community-basednatural resource management. Environmental Management 35,703-715

[9]. Baridam, M.D (2001) Research methods in Administrative sciences. Port Harcourt: Belk Publishers

[10]. Clarke (1993) Survival Skills for New Breed Management today.

[11]. David,J.David(2011) Dynamic capabilities: A guide for managers. Ivy Business Journal.

[12]. Dalziell, E.P and McManus (2004) Resilience, Vulnerability, and Adaptive Capacity: Implications for Systems Performance. University of Canterbury. New Zealand.

[13]. Drucker, P. (1955). The practice of management, Heinemann.

[14]. Durodie, B (2003) Is Real Resilience Attainable? The mMonitor, 2(6). 15-19.

[15]. Erica Saville (2006) Resilience: What does it mean for an organization? CAE Bulletin, March.

[16]. Folke, C., Colding, J., Berkes, F (2003) Synthesis: building resilience and adaptive capacity in social-ecological systems. In: Berkes, F., Colding., Folke, C. (Eds.), Navigating Social-Ecological Systems: Building Resilience for Complexity and Change. Cambridge University Press, Cambridge, UK, 352-387.

[17]. Madni, A.M (2007) Designing for Resilience. ISTI Lecture Notes on Advanced Topics in Systems Engineering

[18]. Mallak, L., Kurstedt, Jr., H., \& Patzak, G. (1997). Planning for crises in project management. Project Management Journal, 28(4), 14-20.

[19]. Mallak,L.A (1999) Toward a Theory of Organizational Resilience. Paper presented at the Portland International Conference on Management of Engineering and Technology (PICMET) Portland.

[20]. McManus, S; Seville, E; Vargo, J. and Brundsdon, D. (2008). Facilitated Process for improving organization Resilience. Natural Hazards Review 9(2), 81-90.

[21]. Mitroff, I. I. (2005). From My Perspective: Lessons from 9/11 Are ompanies Better Prepared Today? Technological Forecasting \& Social Change, 72(3), 375-376.

[22]. Mullins, P. (1996) Building Leadership and Management Capacity. New Zealand.

[23]. Mullins, L.J. (1999) Management and Organisational Behaviour, 5th edn. London: Financial Times | Pitman.

[24]. Mullins,L.J and Aldrich, P. (1998) Integrated Model of Management and Managerial Development” Journal of Management, Vol. 7 No. 3, pp 29-39.

[25]. Christoph, L. L. (1996). The effects of fringe benefits on organizational commitment with the hotel / motel industry. (Doctor of Philosophy Dissertation) Graduate School of Clemson University.

[26]. Nunnally, J C (1978). Psychometric theory, New York

[27]. Nwachukwu, C. C. (2009) Human Resources Management: Port Harcourt. Davidstone Publisher Ltd.

[28]. Seville, E., Brunsdon, D., Dantas, A., Le Masurier., Wilkinson, S., and Vargo, J (2008). Organizational Resilience: Researching the Reality of New Zealand Organization. Journal of Business and Continuity and Emergency Management, 2(2), 258-266. 
[29]. Smith, D. (2002). Crisis management. Retrieved October 6, 2003, from ww.http://216.239.53.100/search?q=cache:RQzGXuasmh0C:www.shef.ac.uk/ mcn/6810/reading/crisisessay.pdf

[30]. Staber, U. and Sydow, J. (2002) Organizational Adaptive Capacity. A Structuration Perspective. Journal of Management Inquiry. Vol.11 No. 4,408-424

[31]. Sutcliff,K and Vogus,T (2003a) Organizing for Resilience. Kim, Cameron., J.E Dulton., R.E Dulton., R.E. Quinn (2003) Eds. San Francisco: Berret- Koehler.

[32]. Sutcliff,K and Vogus,T (2003) Organizing for Resilience (draft):Ann Arbor Michigan: University of Michigan, Department of Management and organizations.

[33]. Sutcliffe, K., \& Vogus, T. (2007). Organizing or resilience: Towards a theory of research and agenda. In ISIC. IEEE International Conference on Systems, Man and Cybernetics, pp. 3418-3422, 7-10 Oct. 2007.

[34]. Teece, J. D., Pisano, G., and Shuen, Amy (2010) Dynamic Capabilities and Strategic Management. Strategic management Journal. 18(7): 509-533

[35]. Teece, J. D (2011) Dynamic Capabilities: A Framework for Profitability. Forthcoming, Ivey Business Journal $4^{\text {th }} \mathrm{Feb}$

[36]. Third International conference on Advanced Management Science (2011) IPEDR Vol. 19.Singapore: IACSIT press.

[37]. Tierney, K. (2003). Conceptualising and Measuring Organizational and Community Resilience: Lessons from the Emergency Response Following the September 11, 2001 Attack on the World Trade Center, Preliminary paper 329. Newark: University of Delaware.

[38]. Umoh. G.I (2009) Management Information System. With Practical case studies. Port Harcourt: Blue Print Limited.

[39]. Wycoff, J. (1995) Transformation Thinking. Pengium Group (USA) Incorporated

[40]. United Nations (2005) Report of the world conference on Disaster Reduction. Kobe, Hyogo, Japan, $18^{\text {th }}-22^{\text {nd }}$ January. Vanguard Newspaper, November $13^{\text {th }}, 2011$. Nigeria.

[41]. Wackins and Marsiek (2000) Dimensins of Learning the Organization Quetionnaire.www.organizational learning .com

[42]. Walker, W.J (1980) Human Resource Planning U.S.A: McGraw-Hilland.

[43]. Walker, B.H., Carpenter, S.R., Anderies, J.M., Abel, N., Cumming, G.S., Janssen, M.A., Lebel, L., Norberg, J., Peterson, G.D., Pritchard, L., (2002) Resilience management in social-ecological systems: a working hypothesis for a participatory approach. Conservation Ecology 6: 14. Online: http://www.consecol.org/vol6/iss1/art14/. Downloaded 16.07.07.

[44]. Weick, K. E., \& Sutcliffe, K. M. (2001). Managing the Unexpected. San Francisco: Jossey-Bass.

[45]. William, M. L; Malos, S.B.; Palmer, D.K. (2002). Benefit system and benefit level satisfaction: An expanded model of antecedents and consequences. Journal of Management, 28(2):195-215. 